\title{
Effect of the addition of different types of oenological commercial tannins on phenolic and sensorial red wine characteristics evolution
}

\author{
António M. Jordão ${ }^{1, \text { a }}$, Sara Muxagata ${ }^{2,3}$, Luísa Fontes ${ }^{1}$, Ana C. Correia ${ }^{1}$, Fernando M. Nunes ${ }^{2}$, and Fernanda Cosme ${ }^{3}$ \\ ${ }^{1}$ Instituto Politécnico de Viseu (CI\&DETS), Escola Superior Agrária, Ranhados, 3500-606 Viseu, Portugal \\ ${ }^{2}$ CQ-VR - Centro de Química de Vila Real, UTAD - Escola de Ciências da Vida e do Ambiente, Departamento de Química, \\ 5000-801 Vila Real, Portugal \\ ${ }^{3}$ CQ-VR - Centro de Química de Vila Real, UTAD - Escola de Ciências da Vida e do Ambiente, Departamento de Biologia e \\ Ambiente, Edifício de Enologia, 5000-801 Vila Real, Portugal
}

\begin{abstract}
The main objective of this work was to understand the effect of the addition of different commercial types of oenological tannins on red wine phenolic compounds and sensorial characteristics evolution. So, six different commercial oenological tannins obtained from different sources at an average dosage recommended by the manufactures were added to a red wine. During 120 wine aging days several phenolic parameters were analyzed (including several individual phenolic compounds by HPLC) and also the sensorial characteristics of the wines. Wines treated with oenological tannins showed higher total phenols and flavonoid phenols and lesser color degradation during the aging time considered. After 120 aging days, wines aged with oenological tannins showed more total and individual anthocyanins and significantly more red color that induced significantly color differences in relation to the untreated wine (especially for the wines treated with condensed tannins). From a sensorial point of view it was also possible to detect a clear differentiation between the wines.
\end{abstract}

\section{Introduction}

In recent years there have been changes in consumer's perception around the world regarding wine quality. Consumers continue to enjoy great wines that require a considerable aging time. However, consumers search for wines with a good quality and cheap price; so winemakers need to produce red wines that are appreciated by these consumers with a competitive price. In this perspective, for red wine production, winemakers have been looking for alternatives such as the use of commercial oenological tannins. Initially proposed as coadjuvants to prevent the wine protein instability and officially authorized by the International Oenological Codex [1], the commercial oenological tannins have recently been introduced into winemaking and also during the wine aging process, especially for red wines.

Oenological tannins are generally classified according to their origin into two groups: hydrolyzable tannins, derived mainly from oak wood or other plant species (composed by glucosides from gallic or ellagic acid), and condensed tannins mainly from grapes but also from quebracho and wood (composed by flavan-3-ol monomer subunits, such as (+)-catechin, (-)-epicatechin, and their gallates).

According to several authors [2-4], there are numerous positive effects by the use of oenological tannins, namely in wine color stabilization, wine structure

a e-mail: antoniojordao@esav.ipv.pt improvement, laccase activity, and elimination of reductive odors. However, while many winemakers have practical experience with commercial oenological tannins addition and tannin suppliers report color enhancement, oxidative protection, flavor and mouthfeel improvements as a consequence of addition of oenological tannins, there are several experimental works that reported contradictory results about the potential benefits of these products. Thus, some authors $[2,3,5]$ reported several evidences of the benefits to wine color from tannin preparations added during red wine vinification and aging while other authors $[6,7]$ reported that they may not always improve the wine characteristics or has a little effect. In addition, it is important to note that the majority of the studies analyze the addition of oenological tannins during the prefermentation and not after the malolactic fermentation and also don't make an evaluation of the wine during a long aging period.

Thus, the aim of this work was to verify the impact of the addition of different commercial types of oenological tannins available in the Portuguese market on the evolution of phenolic and sensorial characteristics of a red wine produced in Dão region and made from one of most important Portuguese red grape variety (Touriga Nacional). Furthermore it is important to note that in general, research on the effect of tannins application has been conducted in wines made with international red grape varieties (such as Cabernet Sauvignon and Merlot) and not by the use of Portuguese red grape varieties. 
Table 1. General characteristics of oenological tannins used and identifying wine codes.

\begin{tabular}{lll}
\hline Oenological tannins & Source & Wine code \\
\hline \multirow{2}{*}{ Condensed tannins } & Grape skin & TPA \\
& & TPB \\
\hline \multirow{3}{*}{ Hydrolyzable tannins } & Quebracho & TGA \\
\cline { 2 - 3 } & \multirow{2}{*}{ Oak wood } & TGB \\
& & TEA \\
\end{tabular}

\section{Material and methods}

\subsection{Material}

At the end of the malolactic fermentation, $15.0 \mathrm{~g} / \mathrm{hL}$ of six different commercial types of oenological tannins were added separately to a wine sample (in a laboratory scale for each essay) according to the codes reported in Table 1. Each oenological tannin was prepared as described by the technical information supplied by the manufacturer. All, treatments were done in duplicate.

\subsection{Methods}

During 120 wine aging days after oenological tannins application, several general phenolic parameters were quantified in wines: total phenols, flavonoid and nonflavonoid compounds [8], total anthocyanins [9], total and polymeric pigments [10], and color intensity and hue [11]. Chromatic characteristics were obtained by calculation of several parameters: $L *(\%)$ (lightness), $a *$ (redness), $b *$ (yellowness), using the CIElab method. To distinguish the color more accurately, the color difference was also calculated $\left(\Delta \mathrm{E}=\left[\left(\Delta L^{*}\right)^{2}+\left(\Delta a^{*}\right)^{2}+\right.\right.$ $\left.\left.\left(\Delta b^{*}\right)^{2}\right]^{1 / 2}\right)$ according to the OIV method [11]. Color differences can be distinguished by the human eye when the differences between $\Delta \mathrm{E}$ values are greater than one units [12]. For (+)-catechin, phenolic acids and individual anthocyanin analysis a HPLC chromatographic system was used following the conditions described by Guise et al. [13] All laboratory measurements were performed in quadruplicate.

Each red wine sample was stored for 24 hours at room temperature $\left(20^{\circ} \mathrm{C}\right)$ before sensorial analysis, which was in a sensorial analysis room with individual booths for each expert. Six expert judges with extensive wine tasting experience, evaluated the red wine samples. The wines were evaluated using different visual, aroma, flavor and taste descriptors. The judges were asked to evaluate the samples on a 1-5 quality point scale (1 being less intense and 5 more intense) for each attribute.

\subsection{Statistical analysis}

The data are presented as mean \pm standard deviation. To determine whether there is a statistically significant difference between the data obtained for the diverse parameters quantified in the red wines, an analysis of variance (ANOVA, one-way) and comparison of treatment means were carried out using the Tukey test $(p<0.05)$. This analysis was performed using SPSS (version 23) software. Principal component analysis (PCA) was also used to analyze the data and study the relations between the red wines with different oenological tannins and their sensorial characteristics. This analysis was performed using Statistica (version 7) software.

\section{Results and discussion}

Table 2 shows the evolution of general phenolic compounds of red wines aged with different oenological tannins during 120 aging days. In general during the aging time considered, red wines where oenological tannins were added showed the highest total phenolic content. However, it was evident that the highest total phenolic content was quantified in red wines where hydrolyzable tannins were added (TGA, TGB, TEA and TEB wines), especially in last aging weeks. For example, after 120 aging days, the content of total phenols varied from 506 (TGA wine) to $529 \mathrm{mg} / \mathrm{L}$ (TEA wine) while for the other wines the values varied from $483 \mathrm{mg} / \mathrm{L}$ (TPA wine) to $496 \mathrm{mg} / \mathrm{L}$ (TPB wine). Similar tendency was detected for flavonoid phenols. It is also important to note that the differentiation between the wines aged with hydrolyzable tannins and the other wines (aged with condensed tannins and standard wine) was more marked between 85 and 120 aging days. Regarding to non-flavonoid phenols evolution it was not possible to detected a clear influence of the use of different oenological tannins. Our results are consistent with previous reports $[2,3,14]$. However, according to Canuti et al. [3], timing of oenological tannins addition and grape characteristics had a significant effect on phenolic parameters results. For these authors, oenological tannins addition during pre-fermentation had also a more significant influence on phenolic parameters than did addition during post-fermentation.

Regarding to total and polymeric pigments content, in general, the addition of the oenological tannins used had only a little effect on wines. It was only possible to detected a significantly impact of the addition of the oenological tannins by the use of hydrolyzable tannins (TEA and TEB wines) after 20 aging days for polymeric pigments. In addition, during the aging time considered, the impact of the use of these hydrolyzable oenological tannins especially in polymeric pigments content, was only significant in TEB wine, especially between 85 and 120 aging days.

Finally, the effects of exogenous tannin addition on the total anthocyanins, color intensity and hue evolution is also shown in Table 2. Thus, for total anthocyanins it can be observed that during the aging time considered, a tendency for a decrease of the values in all red wines (including for standard wine). However, the oenological tannins addition had a positive impact on evolution of these pigments because the wines with oenological tannins showed a less pronounced decrease of the total anthocyanins values over the aging time. This result was independently of the oenological tannin type used. After 120 aging days the total anthocyanins content showed in descending order the following sequence: TGA $(558 \mathrm{mg} / \mathrm{L})>$ TPA $(533 \mathrm{mg} / \mathrm{L})>$ TEB $(530 \mathrm{mg} / \mathrm{L})$ $>$ TPB $(522 \mathrm{mg} / \mathrm{L})>$ TEA $(438 \mathrm{mg} / \mathrm{L})>$ TGB $(419 \mathrm{mg} / \mathrm{L})$ $>$ SW $(240 \mathrm{mg} / \mathrm{L})$. Regarding to color intensity, an increased after different oenological tannin addition was detected. However, the color intensity increase 


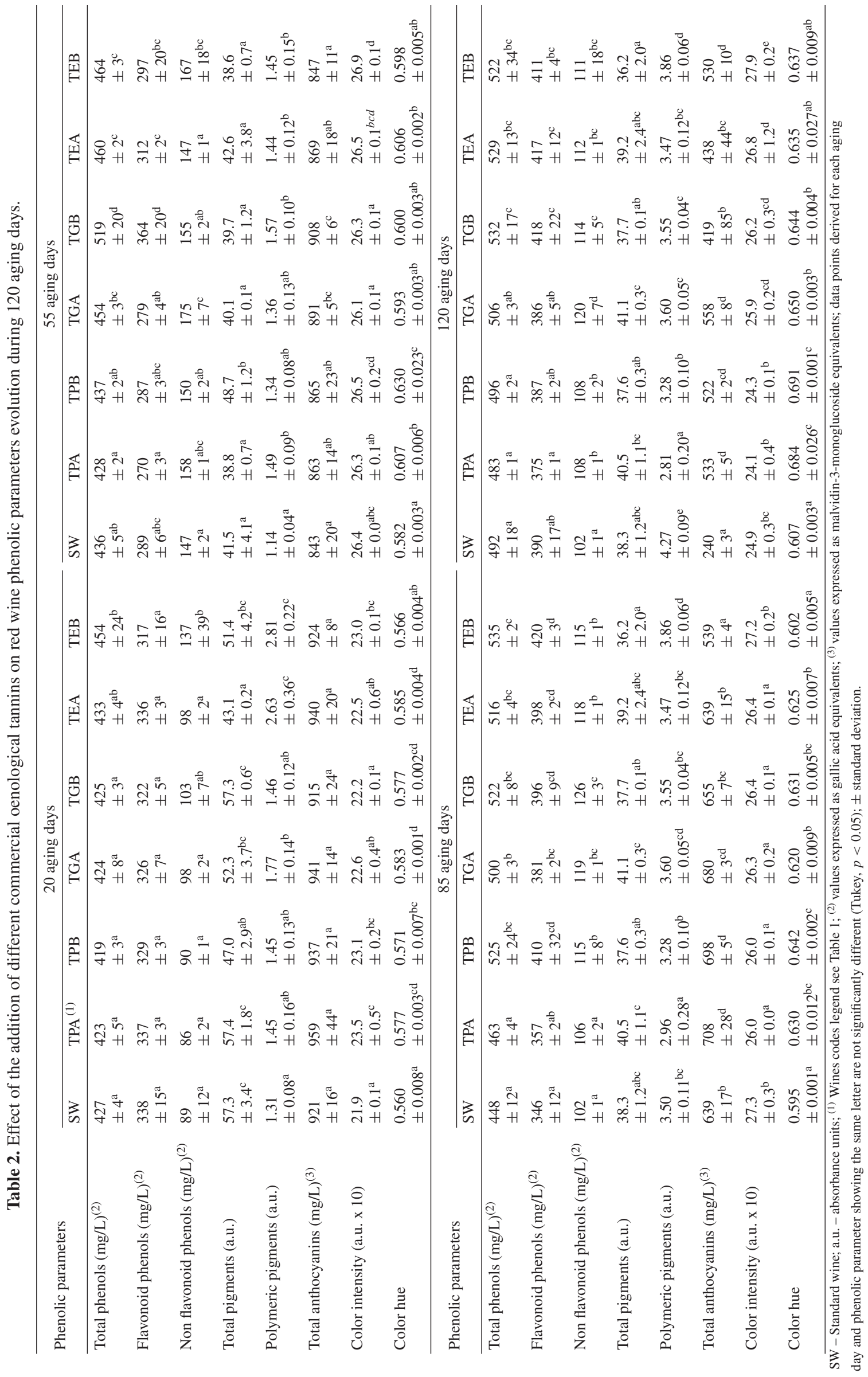




\section{$\boldsymbol{L} *$ values}

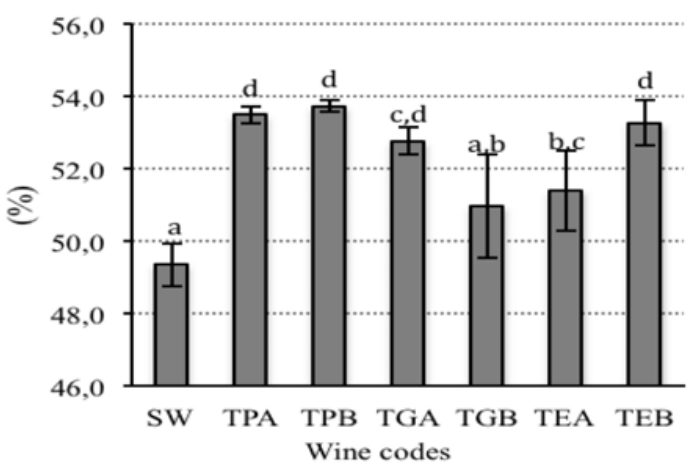

$b^{*}$ values

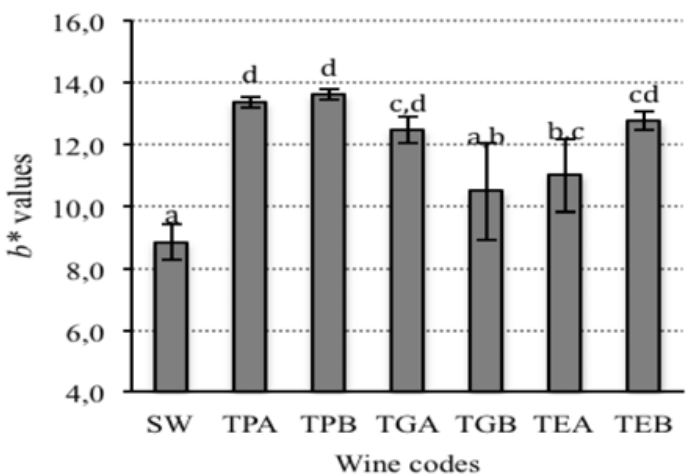

$a^{*}$ values

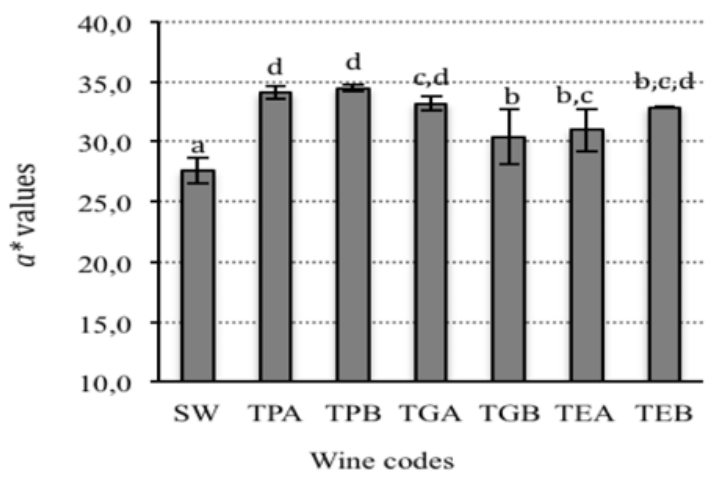

$\Delta E$ values

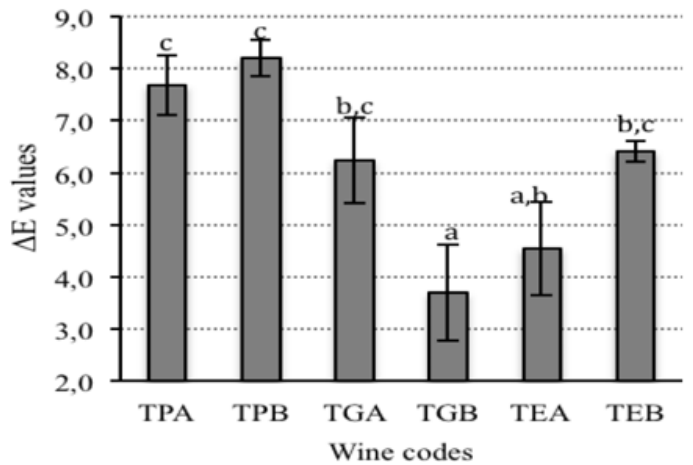

Figure 1. Chromatic characteristics of red wines containing different oenological tannins after 120 aging days. SW - Standard wine; Wines codes legend see Table 1; Data points showing the same letter are not significantly different (Tukey, $p<0.05$ ).

was particularly detected after 20 aging days, especially in wines with oenological tannins containing condensed tannins (TPA and TPB wines) and one of the hydrolyzable tannin used (TEB wine). Several authors [5,15] reported benefits to color intensity in Syrah and various red and rosé wines with the addition of grape-derived tannins. According to Bertrand et al. [16], an increase in red color soon after tannin addition has been attributed to copigmentation effects. During the aging time the impact of the addition of the mentioned oenological tannins reduced but the wines containing oenological tannins with hydrolyzable tannins increased significantly the color intensity values. Thus, considering to the results obtained after 120 aging days, the best color intensity results were obtained for TEB and TEA wines (27.9 and 26.8 a.u., respectively).

Finally, for color hue values, in general the application of condensed tannins (TPA and TPB wines) induced during the aging time an increase of the values in the wines compared to the standard wine (without tannin addition) and the wines with hydrolyzable tannins. This result was particularly evident after 120 aging days.

The results obtained with the CIElab method for the chromatic characteristics of red wines after 120 aging time are shown in Fig. 1. Thus, the addition of all oenological tannins (except for TGB wine) induced a significantly increase in wine lightness $\left(L^{*}\right)$ in all red wines after the aging period considered.

Regarding to $a^{*}$ values (redness), a significantly increased of the values was also obtained as a consequence of the oenological tannins addition. This result was independently of the tannin source used and corresponding to a general improvement of the red color that was also observed in color intensity values (except for TPA and TPB wines) after 120 aging days.

According to the results obtained by Canuti et al. [3], in general the oenological grape seed and gallnut tannins addition improved the red wine color, as a result of higher reactivity with anthocyanins, compared with other onenological tannins. The lowest increase in the $a^{*}$ values for TGB and TEA wines might be explained by the low reactivity of these oenological tannins, as a result of a potential low concentration of tannin and low reactivity and concentration of proanthocyanidins present in these oenological tannins (especially for TEA that is obtained from oak wood). For $b^{*}$ values (yellowness), all oenologocial tannins adition induced a significantly increased of the values with respect to the standard wine. However, between them, TGB and TEA wines showed the lowest increase in $b *$ values. It is important to note that both oenological tannins added has a potential high content of hydrolyzable tannins, especially ellagitannins (in particular TEA wine) that can function as oxidation regulators quickly reacting dissolved oxygen and facilitating the hydroperoxidation of wine constituents and the limited oxidation of wine phenolic compounds prevents the development of yellow color. However, it is relevant to consider that the addition of tannins used in our study did not imply a reduction of yellow color in wines as expected and desirable. 
Table 3. Individual phenolic compounds of red wines containing different oenological tannins after 120 aging days.

\begin{tabular}{|c|c|c|c|c|c|c|c|}
\hline \multirow{2}{*}{ Phenolic compounds (mg/L) } & \multicolumn{7}{|c|}{ Wines ${ }^{(1)}$} \\
\hline & SW & TPA & TPB & TGA & TGB & TEA & TEB \\
\hline Gallic acid & $27.0 \pm 0.7^{\mathrm{a}}$ & $36.0 \pm 3.4^{\mathrm{b}, \mathrm{c}}$ & $30.7 \pm 0.1^{\mathrm{a}, \mathrm{b}}$ & $38.9 \pm 2.9^{c}$ & $89.5 \pm 2.8^{\mathrm{d}}$ & $26.9 \pm 1.7^{\mathrm{a}}$ & $30.3 \pm 0.1^{\mathrm{a}, \mathrm{b}}$ \\
\hline$(+)$-Catechin & $10.5 \pm 5.0^{\mathrm{a}}$ & $10.9 \pm 0.5^{\mathrm{a}}$ & $22.9 \pm 4.5^{\mathrm{b}}$ & $21.9 \pm 3.9^{\mathrm{b}}$ & $8.6 \pm 1.2^{\mathrm{a}}$ & $7.8 \pm 1.03^{\mathrm{a}}$ & $10.9 \pm 0.8^{\mathrm{a}}$ \\
\hline Trans-caftaric acid ${ }^{(2)}$ & $43.1 \pm 6.4^{\mathrm{a}}$ & $53.8 \pm 4.2^{\mathrm{a}}$ & $53.8 \pm 5.8^{\mathrm{a}}$ & $50.2 \pm 8.4^{\mathrm{a}}$ & $53.5 \pm 3.0^{\mathrm{a}}$ & $55.5 \pm 0.5^{\mathrm{a}}$ & $53.9 \pm 1.1^{\mathrm{a}}$ \\
\hline 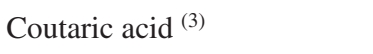 & $12.3 \pm 1.6^{\mathrm{a}}$ & $16.0 \pm 1.3^{\mathrm{a}}$ & $15.5 \pm 1.7^{\mathrm{a}}$ & $14.6 \pm 2.6^{\mathrm{a}}$ & $15.3 \pm 0.4^{\mathrm{a}}$ & $14.7 \pm 1.6^{\mathrm{a}}$ & $15.5 \pm 0.7^{\mathrm{a}}$ \\
\hline Caffeic acid & $24.6 \pm 6.3^{\mathrm{a}}$ & $19.9 \pm 4.1^{\mathrm{a}}$ & $16.9 \pm 6.8^{\mathrm{a}}$ & $23.3 \pm 6.7^{\mathrm{a}}$ & $19.9 \pm 2.9^{\mathrm{a}}$ & $14.5 \pm 3.0^{\mathrm{a}}$ & $10.1 \pm 0.5^{\mathrm{a}}$ \\
\hline Ethyl-caffeic acid ${ }^{(2)}$ & $1.1 \pm 0.5^{\mathrm{a}}$ & $0.7 \pm 0.0^{\mathrm{a}}$ & $0.7 \pm 0.2^{\mathrm{a}}$ & $1.3 \pm 0.8^{\mathrm{a}}$ & $0.7 \pm 0.1^{\mathrm{a}}$ & $0.7 \pm 0.0^{\mathrm{a}}$ & $0.73 \pm 0.1^{\mathrm{a}}$ \\
\hline 4-Hydroxycoumaric acid & $0.06 \pm 0.01^{\mathrm{a}}$ & $0.07 \pm 0.03^{\mathrm{ab}}$ & $0.11 \pm 0.01^{\mathrm{b}}$ & $0.10 \pm 0.00^{\mathrm{ab}}$ & $0.09 \pm 0.04^{\mathrm{ab}}$ & $0.06 \pm 0.01^{\mathrm{a}}$ & $0.05 \pm 0.00^{\mathrm{a}}$ \\
\hline Ferulic acid & $2.2 \pm 0.06^{\mathrm{abc}}$ & $2.4 \pm 0.02^{\mathrm{bc}}$ & $2.4 \pm 0.10^{\mathrm{bc}}$ & $2.5 \pm 0.08^{\mathrm{c}}$ & $2.3 \pm 0.12^{\mathrm{abc}}$ & $2.1 \pm 0.25^{\mathrm{ab}}$ & $1.9 \pm 0.02^{\mathrm{a}}$ \\
\hline Ellagic acid & nd & nd & $0.03 \pm 0.00^{\mathrm{b}}$ & $0.07 \pm 0.01^{\mathrm{c}}$ & $0.02 \pm 0.00^{\mathrm{ab}}$ & $0.02 \pm 0.00^{\mathrm{ab}}$ & $0.01 \pm 0.00^{\mathrm{a}}$ \\
\hline Cya-3-monogluc ${ }^{(4)}$ & $1.2 \pm 0.4^{\mathrm{a}}$ & $10.1 \pm 1.5^{\mathrm{b}}$ & $9.8 \pm 0.6^{\mathrm{b}}$ & $10.0 \pm 0.7^{\mathrm{b}}$ & $6.1 \pm 3.2^{\mathrm{ab}}$ & $4.9 \pm 1.9^{\mathrm{ab}}$ & $0.1 \pm 0.0^{\mathrm{a}}$ \\
\hline Pet-3-monogluc ${ }^{(4)}$ & $1.7 \pm 0.4^{\mathrm{a}}$ & $15.8 \pm 2.3^{\mathrm{c}}$ & $15.7 \pm 1.1^{\mathrm{c}}$ & $15.6 \pm 0.6^{c}$ & $9.9 \pm 2.7^{\mathrm{bc}}$ & $8.6 \pm 2.3^{b}$ & $0.4 \pm 0.1^{\mathrm{a}}$ \\
\hline Peo-3-monogluc ${ }^{(4)}$ & $1.2 \pm 0.2^{\mathrm{a}}$ & $11.5 \pm 0.5^{\mathrm{cd}}$ & $13.5 \pm 0.7^{\mathrm{d}}$ & $12.0 \pm 1.4^{\mathrm{cd}}$ & $7.4 \pm 1.7^{\mathrm{bc}}$ & $5.6 \pm 1.7^{\mathrm{ab}}$ & nd \\
\hline Malv-3-monogluc ${ }^{(4)}$ & $8.9 \pm 1.8^{\mathrm{ab}}$ & $72.8 \pm 5.5^{\mathrm{d}}$ & $69.8 \pm 2.3^{\mathrm{d}}$ & $68.5 \pm 2.9^{\mathrm{d}}$ & $37.9 \pm 11.2^{\mathrm{c}}$ & $35.4 \pm 12.9^{\mathrm{bc}}$ & $1.7 \pm 0.3^{\mathrm{a}}$ \\
\hline Cya-3- acetylgluc ${ }^{(4)}$ & $5.5 \pm 0.3^{\mathrm{ab}}$ & $5.6 \pm 0.3^{\mathrm{ab}}$ & $5.4 \pm 0.0^{\mathrm{ab}}$ & $8.3 \pm 1.5^{\mathrm{b}}$ & $7.7 \pm 1.2^{\mathrm{b}}$ & $4.5 \pm 1.6^{\mathrm{ab}}$ & $3.5 \pm 0.2^{\mathrm{a}}$ \\
\hline Malv-3- acetylgluc ${ }^{(4)}$ & $1.4 \pm 0.6^{\mathrm{a}}$ & $15.8 \pm 1.3^{\mathrm{d}}$ & $15.1 \pm 1.0^{\mathrm{cd}}$ & $14.9 \pm 0.8^{\mathrm{cd}}$ & $10.2 \pm 1.6^{\mathrm{bc}}$ & $7.7 \pm 2.5^{b}$ & $0.1 \pm 0.0^{\mathrm{a}}$ \\
\hline Peo-3-p-coumarylgluc ${ }^{(4)}$ & $1.1 \pm 0.4^{\mathrm{a}}$ & $1.4 \pm 0.3^{\mathrm{a}}$ & $1.4 \pm 0.1^{\mathrm{a}}$ & $1.3 \pm 0.2^{\mathrm{a}}$ & $0.7 \pm 0.3^{\mathrm{a}}$ & $0.5 \pm 0.2^{\mathrm{a}}$ & nd \\
\hline Malv-3-p-coumarylgluc ${ }^{(4)}$ & $0.6 \pm 0.2^{\mathrm{a}}$ & $7.4 \pm 0.6^{\mathrm{c}}$ & $7.2 \pm 0.3^{\mathrm{c}}$ & $6.7 \pm 0.5^{c}$ & $3.8 \pm 1.2^{\mathrm{b}}$ & $2.3 \pm 0.9^{\mathrm{ab}}$ & $0.2 \pm 0.1^{\mathrm{a}}$ \\
\hline
\end{tabular}

The values obtained for color difference (Fig. 1) between the wines aged with oenological tannins and standard wine showed that all wines showed values higher than 1 CIElab units, indicating that the color differences obtained could be detected by human eyes. The highest differences were detected for the wines where condensed tannins were added (TPA and TPB wines). In addition, TGB and TEA wines showed the significantly lowest differences.

Table 3 shows the individual phenolic compounds quantified in red wines containing different oenological tannins after 120 aging days. As expected the significantly highest values of gallic acid was quantified in wines containing hydrolyzable tannins from quebracho (TGA and TGB wines) that usually has high levels of gallic acid in their composition. In addition, high $(+)$-catechin content was quantified in one of the wines containing oenological condensed tannins (TPB wine) and also in wine containing hydrolyzable tannins from quebracho (TGA wine). Ellagic acid content was similar in all wines except in standard wine (ST wine) and TPA wine. All of these results (except for ellagic acid content in some wines) are in general expected considering the botanical origin of these products. Considering to the results obtained for the phenolic acids, the addition of the different oenological tannins didn't have any effect in their content in all red wines.

Regarding to individual anthocyanins, in general after 120 aging days, significantly higher values of monoglucosides were detected in wines treated with oenological tannins (except for TEB wine). Monoglucosides derivatives forms are the major quantitiative anthocyanin group and are stable molecules and their presence gives stability to the wine, because these compounds are relatively resistant to oxidant process. Thus, the addition of oenological tannins incresead also the resistence of red color against degradation during the aging time. In general, these results for individual anthocyanins are in line with the results obtained for the levels of total anthocyanin concentration, color intensity and $a *$ values quantified in the various wines.

Finally, to highlight the relationship between red wine aged with different oenological tannins and their sensorial profile, principal component analysis (PCA) was carried out using the data obtained from the sensorial analyses after 85 aging days (Fig. 2) in order to study the main sources of variability and the relationship between the impact of the different oenological tannins. Thus, Fig. 2 shows the corresponding loading plots that established the relative importance of each variable.

The PCA obtained, showed that the first two PCs explained $73.67 \%$ of the total variance. The first PC (PC1, $55.72 \%$ of the variance), was positively correlated with the variable AQ, FF, ST, AP and RFF and negatively correlated with CI, VF, VA and WA. The second PC (PC2, 17.95\% of the variance) was positively correlated with CL and TP and negatively correlated with NFF. After cluster analysis, two groups are formed by the wine aged with tannins TPB, TPA, TEA and TEB; these wines are positioned in the left side of the PCA. The other group is formed by wine 


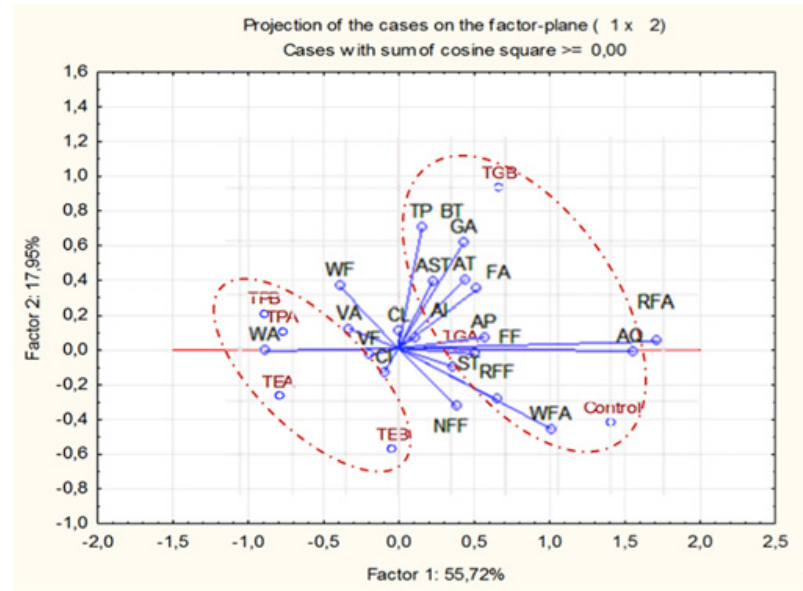

Figure 2. Principal component analysis score plot for sensorial parameters of wines aged with different commercial oenological tannins after 85 aging days. Control - Standard wine; Wines codes legend see Table 1; sensorial parameters: CI- Color intensity; CL- Color limpidity; AI- Aroma intensity; WFAWild fruits aroma; RFA- Red fruit aroma; WA- Wood aroma; FA- Floral aroma; VA- Vegetal aroma; AP- Aroma persistence; AQ- Aroma quality; GA- global appreciation; AT- Acidity taste; ST- Sweet taste; BT- Bitter taste; TP- Persistence taste; AST- Astringency taste; VF- Vegetal flavor; FF- Floral flavor; WF- Wood flavor; RFF- Red fruit flavor; WFF- Wild fruit flavor.

aged with TGA, TGB and the wine without tannin addition (standard wine); these wines are positioned in the right side of the PCA.

\section{Conclusions}

This study has identified the potential impact of the addition of the different commercial oenological tannins studied during the red wine aging process. In general, red wines treated with oenological tannins showed during the aging time higher resistence to red color degradation. However, it was not possible to detected a clear differenciation between condensed and hydrolyzable tannins. From the sensorial characteristics point of view, different characteristics were evident between the wines treated with the different oenological tannins.

We hope that further studies will be able to elucidate more specific impacts of the use of these oenological products in wine characteristics and try to explain the potential relationship among grape characteristics, tannin addition (including different concentration added), and wine chemical and sensory properties.

FCT - Fundação para a Ciência e Tecnologia, I.P., under the project UID/Multi/04016/2016. Furthermore we would like also to thank the Instituto Politécnico de Viseu (CI\&DETS), Chemical Research Centre of Vila Real (CQ-VR) and University of Trás-os-Montes and Alto Douro (School of Life Sciences and Environment) for their support.

\section{References}

[1] OIV 2009. International Oenological Codex. Organisation Internationale de la Vigne et du Vin. Paris, France

[2] A. Crespy, Rev. des Enol. 30, 38-39 (2003)

[3] V. Canuti, S. Puccioni, G. Giovani, M. Salmi, I. Rosi, M. Bertuccioli, Am. J. Enol. Vitic. 63, 220-231 (2012)

[4] H. Fulcrand, M. Dueñas, E. Salas, V. Cheynier, Am. J. Enol. Vitic. 57, 289-297 (2006)

[5] L. Lurton, M. Laurent, C. Garnier, Rev. des Enol. 104, 27-28 (2002)

[6] D. Obradovic, Grape-derived tannins and their application. Aust. N. Z. Grapegr. Winemaker, 509, 66-73 (2006)

[7] E. Revilla, J.M. Ryan, V. Kovac, J. Nemanic, In Food Flavours: Formation, Analysis and Packaging Influences (E.T. Contis et al. editors, 1998)

[8] T.E. Kramling, V.L. Singleton, Am. J. Enol. Vitic. 20, 86-92 (1969)

[9] P. Ribéreau-Gayon, E. Stronestreet, Bull Soc. Chim. 9, 2649-2652

[10] T.C. Somers, M.E. Evans, J. Sci Food and Agric. 28, 279-287 (1977)

[11] OIV (2012). International Oenological Codex. Edition Officielle, Paris

[12] J.F Gonnet, Food Chem. 63, 409-415 (1998)

[13] R. Guise, L. Filipe-Ribeiro, D. Nascimento, O. Bessa, F.M. Nunes, F. Cosme, Food Chem. 156, 250-257 (2014)

[14] M. Parker, P.A. Smith, M. Birse, I.L. Francis, M.J. Kwiatkowski, K.A. Lattey, B. Liebich, M.J. Herderich, Aust. J. Grape Wine Res. 13, 30-37 (2007)

[15] A. Crespy, Rev. Fr. CEnol. 195, 23-28 (2002)

[16] A. Bertrand, R.M. Canal-Llaubéres, M. Feuillat, G. Hardy, F. Lamadon, A. Lonvaud-Funel, P. Pellerin, N. Vivas, In Produits de traitement et auxiliaires d'élaboration des mouts et des vins (Eds. Féret, 2000) 